Epidemiology and prevention strategies for the musculoskeletal injuries in the paddle-tennis senior players

\section{R. Castillo-Lozano}

Lecturer Physiotherapy Department at University of Osuna, Seville, Spain

Keywords: Injury prevention; Racquet-sport; Physiotherapy; Seniors

Objective. To describe the incidence of musculoskeletal injuries in paddle-tennis senior players.

Method. The sample was composed of 131 active paddle-tennis senior players ( 107 men / 24 women); with a mean age of $56.8 \pm 4.6$ years [ 50 to 66 years] and $1.76 \pm 0.07 \mathrm{~m}, 81.3 \pm 16.44 \mathrm{~kg}$ and an average play time of $9.36 \pm 6.34$ years. The $39.7 \%$ played at the right position; $79.4 \%$ over the medium level, $91.6 \%$ were right-hand and $62.6 \%$ were federated. Participants were asked about the injuries they had suffered during their paddle-tennis career and completed the International Physical Activity Questionnaire (IPAQ).

Results. The results showed that specific joint lesions due to paddle-tennis are located mainly in the elbow (29.8\%), lower back (27.5\%), knee (22.9\%), tennis leg (22.1\%) and shoulder (20.6\%).

Conclusions. Paddle-tennis creates specific demands on the musculoskeletal system of senior players, with acute injuries, such as knee sprains, being more frequent in the lower extremity while chronic overuse injuries, such as lateral epicondylitis and shoulder pain are more common in the upper extremity, and low back pain in the trunk in the senior players. The main injury risk factors observed were age, laterality and body mass index. These findings could help physiotherapists to create preventive programmes.

http://dx.doi.org/10.1016/j.ramd.2015.08.010

\section{Entrenamiento de fuerza mediante una periodización ondulante en jugadores de pádel}

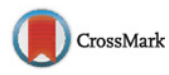

\section{J. González Castellanos}

Facultad de ciencias del deporte. Universidad de Castilla la Mancha

Palabras clave: Deportes de raqueta; Fuerza; Entrenamiento; Condición física

Objetivo. El objetivo de este estudio ha sido comparar los efectos de un programa de entrenamiento de fuerza de 6 semanas, 3 sesiones semanales siguiendo una periodización ondulante en jugadores de pádel entrenados, analizando sus efectos sobre el tren inferior, tren superior y estabilidad del Core.

Método. Para este estudio se han reclutado un total de 16 participantes varones, divididos en dos grupos, experimental $(\mathrm{n}=8)$ y control $(\mathrm{n}=8)$, físicamente activos, $21.37 \pm 18$ años de edad, $181 \pm 4.50 \mathrm{~cm}$ de altura, $74.87 \pm 6.10 \mathrm{~kg}$ de peso para el grupo experimental y $22.12 \pm 1.80$ años de edad, $182.25 \pm 6.11 \mathrm{~cm}$ de altura, $75.25 \pm 6.96 \mathrm{~kg}$ de peso para el grupo control. Para cuantificar los efectos del entrenamiento en ambos grupos se realiza un pre test y un post test. Los test utilizados en el estudio han sido: test de fuerza de tren superior, en el que incluía las variables lanzamiento de balón medicinal frontal (BMF), balón medicinal derecha (BMD) y lanzamiento de balón medicinal revés (BMR), un test de fuerza del tren inferior que incluía las variables salto horizontal $(\mathrm{SH})$ y salto cuádruple (SC) y un test de la estabilidad del Core que incluía las variables abdominales (ABD), plancha lateral derecha (PLD), plancha lateral izquierda (PLI) y lumbares (LUM).

Resultados. Los resultados obtenidos muestran que se han encontrado diferencias significativas entre grupos (experimental/control), a lo largo del periodo de entrenamiento en las variables BMF, BMR, SH, SC, ABD, PLI y LUM. Las variables BMD y PLD no han mostrado diferencias significativas a lo largo del periodo de entrenamiento entre los grupos. El grupo experimental ha tenido unas mejoras del $10.66 \%, 10.21 \%$ y $6.27 \%$ respectivamente en las variables del tren superior. El nivel de significación ha sido $\mathrm{P}<0.05$.

Conclusiones. Tras las 6 semanas de entrenamiento que han seguido los participantes del presente estudio, se han producido efectos de mejora en los niveles de fuerza y por lo tanto la condición física de los sujetos se ha visto mejorada.

http://dx.doi.org/10.1016/j.ramd.2015.08.011

\section{Análisis de la ansiedad antes de la competición en el Campeonato de Madrid de primera categoría femenina de pádel}

\section{G. Sáez Rodríguez, M. Merino Fernández, R. Ortega Cuello, J. Acebes Sánchez}

Universidad Francisco de Vitoria (UFV)

Palabras clave: Deportes de raqueta; Ansiedad; Competición; mujeres

Introducción. La ansiedad ha sido muy estudiada dentro del mundo del deporte. Se ha comprobado en trabajos anteriores que algunos fracasos en competición son debidos a un mal manejo de la ansiedad. Se puede entender la ansiedad como un estado emocional negativo que incluye sensaciones de nerviosismo, preocupación y aprensión, relacionadas con la activación del organismo, de ahí la importancia de realizar un buen trabajo psicológico en deportistas de un determinado nivel. A la hora de hablar de deporte, el componente mental (ansiedad cognitiva) tiene mucha importancia. Una situación deportiva comprende las expectativas y cogniciones negativas de éxito sobre uno mismo ante una situación, y su autoevaluación que puede originar cuatro tipos de consecuencias mentales negativas: a) preocupaciones y otros pensamientos negativos, b) imágenes desastrosas y otros problemas de autoevaluación imaginada, c) problemas de concentración y de mantener el foco de atención, d) problemas de control del cuerpo. En este estudio se analiza la ansiedad de un grupo de jugadoras participantes en el Campeonato por equipos de primera categoría de pádel de Madrid.

Método. Para llevar a cabo el estudio se ha pasado el test de ansiedad deportiva de Martens (CSAI-2) a un total de 16 jugadoras participantes en el Campeonato de Madrid por equipos de $1 \stackrel{a}{a}$ categoría de pádel de la FMP. El campeonato tuvo lugar del 11 al 15 de febrero de 2015 en las instalaciones del Duet Sport de Las Rozas. Todas las jugadoras compiten en $1 \underline{a}$ o $2 \underline{a}$ categoría en la FMP y tienen edades comprendidas entre los 21 y 42 años.

Resultados. Los resultados obtenidos tras pasar los cuestionarios indican que para la medida de ansiedad cognitiva, la media de las puntuaciones directas de las mujeres que participaron en el Campeonato de pádel por equipos de primera categoría, es de 25.6 lo cual tras comprobar los baremos del Test de Martens CSAI-2 equivale a una ansiedad cognitiva media-alta. En lo que respecta a la ansiedad somática, esta indica que es un factor más controlado, ya que la media de las puntuaciones directas de las deportistas se sitúa en 18. Analizando este dato con lo indicado en el baremo, se comprueba que el nivel de ansiedad a nivel somático de las jugadoras estaría clasificado como medio. Por último, los datos que revelan la autoconfianza de las jugadoras son bastante elevados, estando la media de las puntuaciones directas en 28 . Con este parámetro, se puede decir que la autoconfianza que tienen las participantes es alta, dato que se puede contrastar con la realidad de las deportistas: varias de ellas son jugadoras que juegan partidos de World Padel 